\title{
(2) OPEN ACCESS \\ Mortality in a cohort of 3.1 million children, adolescents and young adults
}

\author{
Joel G Ray (1) 1, ${ }^{1,2,3}$ Astrid Guttmann, ${ }^{3,4}$ Jose Silveira, ${ }^{2}$ Alison L Park ${ }^{3}$
}

- Additional material is published online only. To view, please visit the journal online (http://dx.doi.org/10.1136/ jech-2019-213365)

'Medicine, and Obstetrics and Gynecology, St. Michael's Hospital, University of Toronto, Toronto, Ontario, Canada ${ }^{2}$ Psychiatry, University of Toronto, Toronto, Ontario, Canada

${ }^{3}$ ICES, Toronto, Ontario, Canada ${ }^{4}$ Pediatrics, Hospital for Sick Children, Toronto, Ontario, Canada

Correspondence to Dr Joel G Ray, Medicine, and Obstetrics and Gynecology, St. Michael's Hospital, University of Toronto, Toronto, M5B 1W8, Canada; joel.ray@unityhealth.to

Received 14 October 2019 Revised 9 December 2019 Accepted 15 December 2019 Published Online First 8 January 2020

\author{
ABSTRACT \\ Background Many youth deaths occur in the first \\ year of life, from prematurity and anomalies. Detailing \\ mortality after age 1 year may differentially guide \\ preventive strategies in children, adolescents and young \\ adults.
}

Methods A cohort study in Ontario, Canada comprised 3139698 children born from 1990 to 2016. Adjusted HR (aHR) for death between 1 and 24 years were generated, comparing demographic variables and parity.

Results After a median of 13.7 years of follow-up, 6930 deaths occurred between ages 1 and 24 years (incidence rate 17.0 per 100000 person-years), peaking at age 23 years (43.7 per 100 000). The aHR for death was higher among males than females $(1.44,95 \% \mathrm{Cl}$ 1.37 to 1.51$)$, rural versus urban areas $(1.48,95 \% \mathrm{Cl}$ 1.39 to 1.58), lowest versus highest income areas (1.39, $95 \% \mathrm{Cl} 1.29$ to 1.51$)$ and at parity $1(1.16,95 \% \mathrm{Cl} 1.10$ to 1.23$)$, parity $2(1.34,95 \% \mathrm{Cl} 1.23$ to 1.45$)$, parity $3+(1.96,95 \% \mathrm{Cl} 1.74$ to 2.21$)$, each relative to a child without an older sibling. Among males, the proportion of deaths due to injury jumped from $30 \%$ before age 15 years to $65 \%$ thereafter, and in females, from $28 \%$ to $51 \%$. Intentional self-harm/assault explained $11 \%$ of injury-related deaths among males before age 15 years, and $20 \%$ thereafter, with respective figures of $18 \%$ and $17 \%$ for females. Deaths outside of hospital increased with age, from $35 \%$ at age 1 year, to $66 \%$ at age 22 years.

Conclusion There is a heightened susceptibility of dying starting at age 15 years, especially among males, from injury, and arising outside of hospital.

\section{INTRODUCTION}

The death of a child, adolescent or young adult is an untimely event, whose tragic loss is experienced by the parents, siblings, friends and caregivers of the deceased. ${ }^{1}$ Across the life course, males and persons of lower socioeconomic status are especially at increased risk of death, ${ }^{2}$ as are those affected by mental illness. ${ }^{3}$ Although rates of infant and youth mortality have been in decline for decades worldwide, ethnic disparities continue to exist in highincome countries, such as the USA, where American Indian and black youths have much higher rates of death compared with Asian, Hispanic and white youth. ${ }^{2}$ Even so, mortality rates in young and middle-aged white adults seem to have stagnated in the USA, especially in rural areas, due to increases in unintentional drug poisonings and suicide. ${ }^{45}$ Recent Canadian data observed a resurgence in adult deaths due to the opioid epidemic. ${ }^{6}$ However, relatively little work has focused on patterns of mortality in children and emerging adults.

A large proportion of childhood deaths occur in the first year of life-largely from causes which are not readily preventable such as a lethal congenital or chromosomal anomaly, prematurity or sudden infant death syndrome. 8 Therefore, analysing childhood mortality after 1 year of age might provide insight about risk factors and causes of death-due to injury and otherwise-that are preventable, especially since the median age at which a child can walk unassisted is 12 months. ${ }^{9}$

Linkage of mortality to other health and demographic data may offer new opportunities for 'precision public health' approaches among identified higher risk groups. Hence, the current study capitalised on multiple linked health and demographic linked data from Ontario-Canada's most populous province, which provides universal access to all primary and acute healthcare services. A novel birth cohort was created to explore associations of maternal immigration, time-varying income status, sibling order and cause of death among youths aged 1-24 years, further delineated by 1 year age groups.

\section{METHODS}

A population-based birth cohort study was completed within the entire province of Ontario, Canada. Included were children born in Ontario between 1 April 1990 and 31 March 2016, and who were alive at age 366 days after birth. Other reasons for study exclusion are outlined in online supplementary files 1 and 2 .

All hospital births were identified using administrative health databases, described elsewhere ${ }^{7}$ and detailed in online supplementary file 1 . These datasets were linked using unique encoded identifiers and analysed at ICES. The linked datasets include the Ontario Office of the Registrar General Vital Statistics Deaths, which comprises mandatory completed death certificate information, coded according to the International Classification of Diseases (ICD), ninth revision, as well as the Ministry of Health's Registered Persons Database, which contains vital status and sociodemographic information for all individuals ever eligible for the Ontario Health Insurance Plan. Maternal world region of origin was identified using the Immigration, Refugees and Citizenship Canada's Permanent Resident Database, which contains data on country of citizenship for immigrants to Canada from 1985 onwards. Women not linked to this database were classified as Canadian-born/long-term resident. Linkage rates with the healthcare identifier for both datasets are high. ${ }^{10}$ Income quintile and rural 
Table 1 Characteristics of the children included in the cohort, and that of their mothers, contrasted by standardised differences

\begin{tabular}{|c|c|c|c|}
\hline Characteristic & $\begin{array}{l}\text { Male children } \\
(n=1609644)\end{array}$ & $\begin{array}{l}\text { Female children } \\
(n=1530054)\end{array}$ & $\begin{array}{l}\text { Standardised } \\
\text { difference }\end{array}$ \\
\hline \multicolumn{4}{|l|}{$\begin{array}{l}\text { Of the mother at the } \\
\text { birth }\end{array}$} \\
\hline Mean (SD) age, years & $29.6(5.4)$ & $29.6(5.4)$ & 0.00 \\
\hline $\begin{array}{l}\text { Median (IQR) number of } \\
\text { previous live births }\end{array}$ & $\begin{array}{l}1.0(0.0- \\
1.0)\end{array}$ & $\begin{array}{l}1.0(0.0- \\
1.0)\end{array}$ & 0.00 \\
\hline No previous live birth & 790081 (49.1) & 751990 (49.1) & 0.00 \\
\hline $\begin{array}{l}\text { Any previous live } \\
\text { birth }\end{array}$ & $564351(35.1)$ & $536816(35.1)$ & 0.00 \\
\hline $\begin{array}{l}\text { Missing information } \\
\text { on previous live birth }\end{array}$ & $3782(0.2)$ & $3624(0.2)$ & 0.00 \\
\hline \multicolumn{4}{|l|}{$\begin{array}{l}\text { Maternal world region } \\
\text { of origin }\end{array}$} \\
\hline $\begin{array}{l}\text { Canada/long-term } \\
\text { resident/missing* }\end{array}$ & $1257056(78.1)$ & $1196246(78.2)$ & 0.00 \\
\hline Sub-Saharan Africa & $26199(1.7)$ & $27224(1.7)$ & 0.00 \\
\hline Caribbean & $21602(1.4)$ & 22439 (1.4) & 0.00 \\
\hline $\begin{array}{l}\text { Middle East/North } \\
\text { Africa }\end{array}$ & $33720(2.1)$ & $32508(2.1)$ & 0.00 \\
\hline South Asia & $98887(6.1)$ & 93168 (6.1) & 0.00 \\
\hline Hispanic America & $28318(1.8)$ & $27123(1.8)$ & 0.00 \\
\hline $\begin{array}{l}\text { Western Nations/ } \\
\text { Europe }\end{array}$ & $59502(3.7)$ & $56185(3.7)$ & 0.00 \\
\hline East Asia/Pacific & $82410(5.1)$ & $76941(5.0)$ & 0.00 \\
\hline \multicolumn{4}{|l|}{ Of the child } \\
\hline $\begin{array}{l}\text { Mean (SD) birth } \\
\text { weight, } g\end{array}$ & 3440 (585) & $3322(555)$ & 0.21 \\
\hline $\begin{array}{l}\text { Mean (SD) gestational } \\
\text { age at birth, weeks }\end{array}$ & $38.0(1.8)$ & $38.0(1.8)$ & 0.02 \\
\hline$<28$ & $3734(0.2)$ & $3418(0.2)$ & 0.00 \\
\hline $28-31$ & $10089(0.6)$ & $8377(0.6)$ & 0.01 \\
\hline $32-36$ & $109153(6.8)$ & $92890(6.1)$ & 0.03 \\
\hline $37+$ & $1486668(92.4)$ & $1425369(93.2)$ & 0.03 \\
\hline Multiple birth & $46496(2.9)$ & $45786(3.0)$ & 0.01 \\
\hline $\begin{array}{l}\text { Any congenital or } \\
\text { chromosomal anomaly } \\
\text { diagnosed before age } \\
1 \text { year }\end{array}$ & $131134(8.2)$ & $96264(6.3)$ & 0.07 \\
\hline \multicolumn{4}{|l|}{$\begin{array}{l}\text { Income quintile (Q) at } \\
\text { age } 1 \text { year }\end{array}$} \\
\hline Q1 & $350902(21.8)$ & 334349 (21.9) & 0.00 \\
\hline Q2 & 319496 (19.9) & 303669 (19.9) & 0.00 \\
\hline Q3 & $324957(20.2)$ & 309245 (20.2) & 0.00 \\
\hline Q4 & 331985 (20.6) & 314879 (20.6) & 0.00 \\
\hline Q5 & $273672(17.0)$ & $259521(17.0)$ & 0.00 \\
\hline Missing & $8632(0.54)$ & $8391(0.6)$ & 0.00 \\
\hline \multicolumn{4}{|l|}{ Residence at age 1 year } \\
\hline Urban & $1429301(88.8)$ & $1358953(88.8)$ & 0.00 \\
\hline Rural & $178576(11.1)$ & $169416(11.1)$ & 0.00 \\
\hline Missing & $1767(0.1)$ & $1685(0.1)$ & 0.00 \\
\hline $\begin{array}{l}\text { Median (IQR) age at } \\
\text { end of study follow-up, } \\
\text { year }\end{array}$ & $\begin{array}{l}13.7(7.7- \\
20.4)\end{array}$ & $\begin{array}{l}13.7(7.7- \\
20.4)\end{array}$ & 0.00 \\
\hline
\end{tabular}

All data are presented as a number (\%), unless otherwise indicated.

*Includes 170 women with missing information on immigrant country of origin. residence were from Statistics Canada census data. The use of data in this project was authorised under section 45 of Ontario's Personal Health Information Protection Act, which does not require review by a Research Ethics Board or informed consent.

\section{Data analyses}

The characteristics of the male and female children included were presented as either a proportion, median (IQR) or mean (SD), and contrasted by a standardised difference for each. For variables with missingness, which was always under $1 \%$, we reported the proportion that were 'missing'.

Mortality rates (per 100000 children) and 95\% CIs were calculated by 1 year age groups, starting at age 366 days after birth, and ending at the 24th completed year of age, while accounting for the changing number of children in the cohort at risk within each 1 year age interval. Mortality rates and unadjusted rate ratios (RR) at each 1 year age increment were then presented by sex (males vs females), rural vs urban residence (updated at each year of age increment) and income quintile (lowest (Q1) vs highest (Q5)) (updated at each year of age increment).

HRs for child death between ages 1 and 24 years were generated using marginal Cox regression, comparing 1) males versus females; 2) rural versus urban residence, time-varying at each year of age for a given child; 3) residential income Q1, Q2, Q3 or Q4 versus Q5, time-varying at each year of age for a given child and 4) maternal world region of origin (Caribbean, East Asia/Pacific, Hispanic America, Middle East/North Africa, South Asia, sub-Saharan Africa, Western Nations/Europe vs Canada/long-term resident/missing). All HRs were adjusted for maternal factors (World region of origin, age and liveborn parity (ie, number of prior live births) at the child's birth) and child factors (year of birth, sex, preterm birth $<37$ weeks' gestation, a congenital or chromosomal anomaly diagnosed before age 1 year-as well as time-varying residential income quintile and rurality, updated at each year of age). World region analyses were restricted to children residing in an urban area at age 1 year, since most immigrants to Canada settle within a city, where there is generally consistent access to primary healthcare. In each analysis, the proportion of missingness was described, and a corresponding adjusted $\mathrm{HR}$ was generated for that missing group.

As they are often preventable ${ }^{11}$ the proportion $(95 \% \mathrm{CI})$ of all deaths due to injury (defined below) was calculated by 1 year age groups, for males and females, separately. The trend in the proportion of injury-related deaths was assessed by age using a non-parametric Jonckheere-Terpstra test. ${ }^{12}$ All deaths due to injury were then presented by injury subtype: intentional (self-harm (ICD-9 E950-E959) or assault/homicide (ICD-9 E960-E969)) versus unintentional (transport accident (ICD-9 E800-E849), accidental poisoning/overdose (ICD-9 E850-E854) or other/intention unknown (ICD-9 E855-E949, E970-E999 and 800-999). We assumed that a death occurring outside of a hospital might be a proxy for an unanticipated death, such as by suicide or opioid overdose, ${ }^{13}$ and that this would be more common in the adolescent years. Hence, within each 1 year age group, we also calculated the proportion $(95 \% \mathrm{CI})$ of all deaths occurring outside of hospital (ie, outside of an emergency department, inpatient setting, same-day surgery setting or psychiatric hospital) (online supplementary file 1). Therein, unadjusted RRs were calculated comparing the proportion of out-of-hospital deaths among males versus females within each 1 year age increment.

There is a documented higher risk of infant and childhood mortality with rising parity, ${ }^{14}{ }^{15}$ but less is know about that risk 


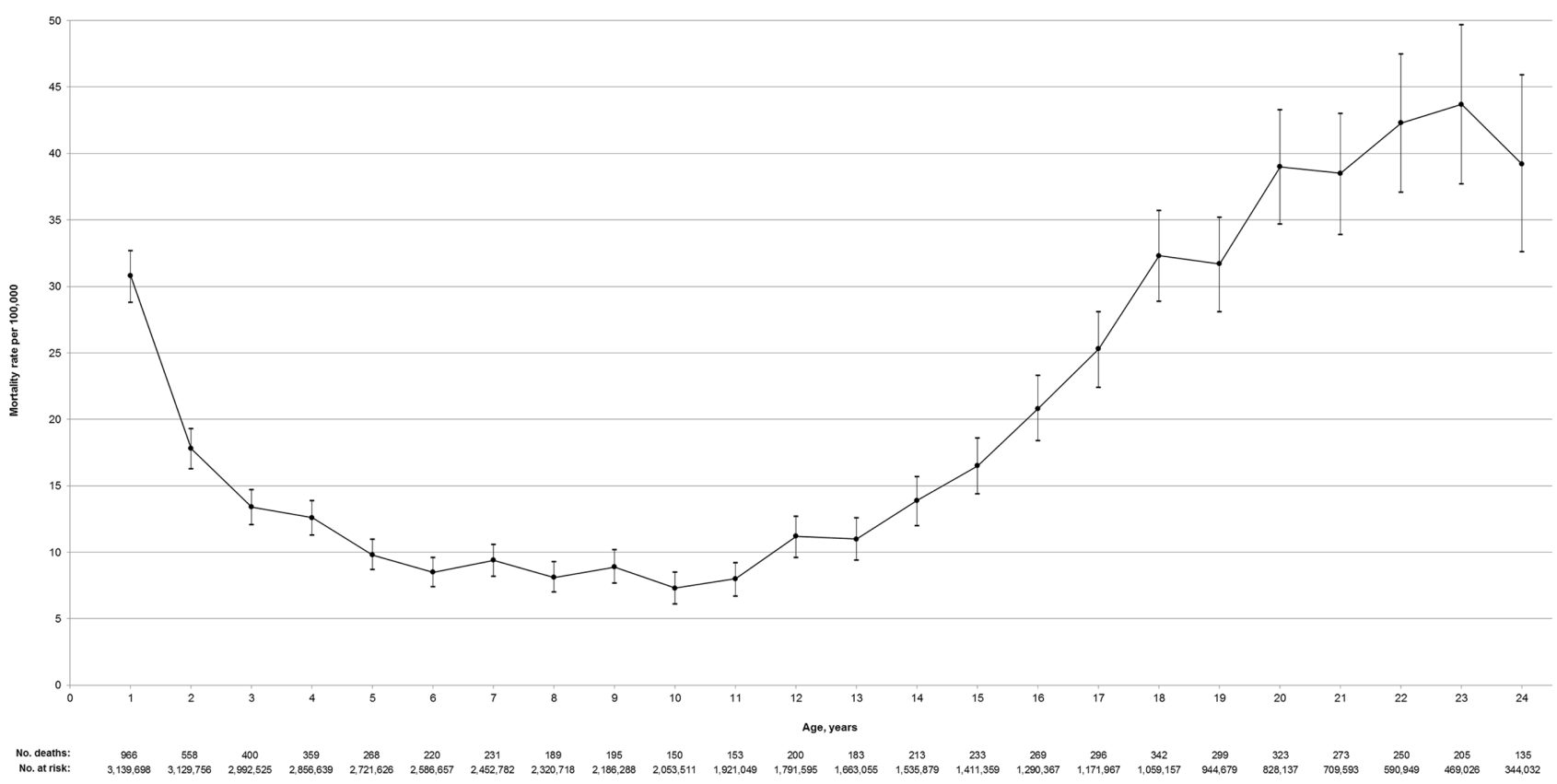

Figure 1 Risk of death among a cohort of 3139698 Canadian children, adolescents and young adults aged 1-24 years. Shown on the Y-axis are age-specific mortality rates and $95 \% \mathrm{Cls}$, and below the $\mathrm{X}$-axis the number at risk and the number of deaths within each age group.

in adolescence, especially deaths from injury. Accordingly, HRs for any death, as well as deaths due to injury or non-injury, were calculated by maternal parity (ie, the number of preceding liveborn siblings-1, 2 or $3+$ vs 0 ). HRs were adjusted for the same covariates as in preceding marginal Cox regression models, except for liveborn parity.

Finally, in an effort to minimise unmeasured confounding due to early environmental or genetic factors, ${ }^{16}$ a sibling analysis was done comparing the risk of death among males versus females aged 1-24 years. From all available children who survived to age 1 year, and who had at least one sibling of the opposite sex also born in the study period, we randomly selected one boy and one girl sibling from an eligible family. Marginal Cox regression accounted for the matching process, and HRs were adjusted for maternal age and parity at the child's birth, as well as for prematurity $<37$ weeks' gestation and a congenital or chromosomal anomaly up to age 365 days.

This study is reported according to the Strengthening the Reporting of Observational Studies in Epidemiology guideline (online supplementary file 3).

\section{RESULTS}

There were 3400353 births in the study period, of which 3139698 children (92.4\%) were alive at age 1 year and residing in Ontario. Other reasons for exclusion are shown in online

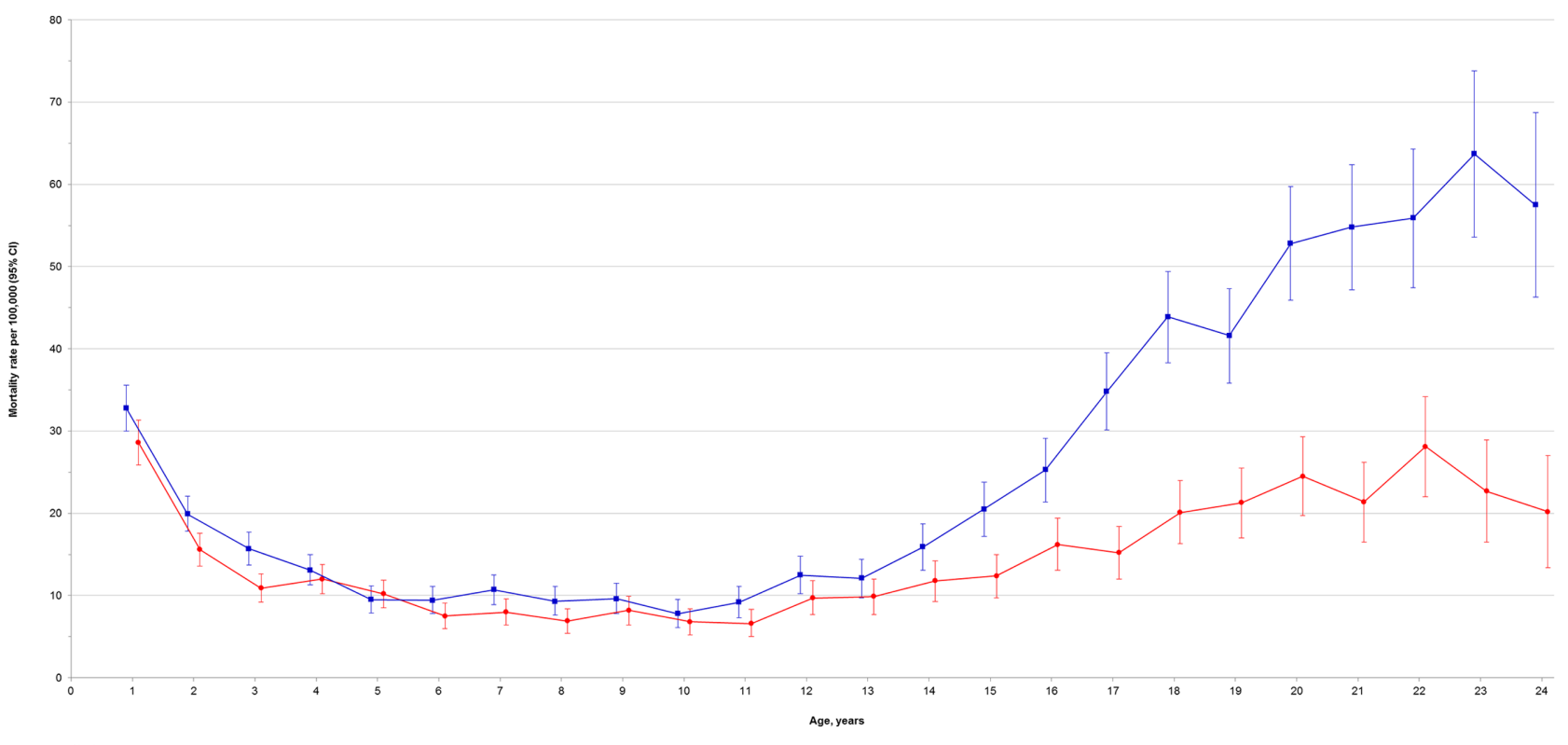

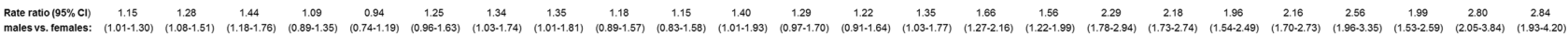

Figure 2 Risk of death among male (blue) and female (red) Canadian children, adolescents and young adults aged 1-24 years. Shown on the Y-axis are age-specific mortality rates and $95 \% \mathrm{Cls}$, and below the $\mathrm{X}$-axis are rate ratios for mortality comparing males vs females within each age group. 


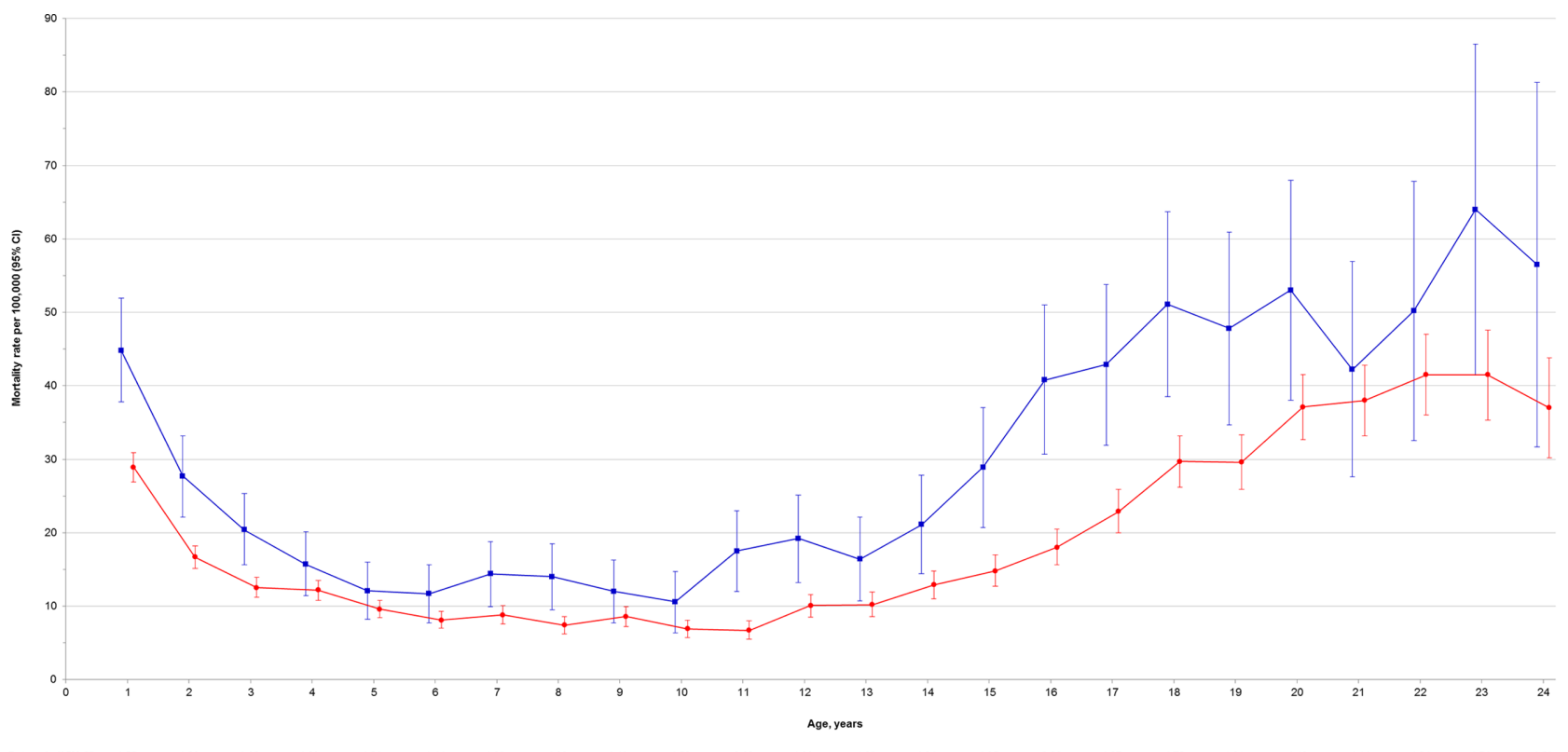

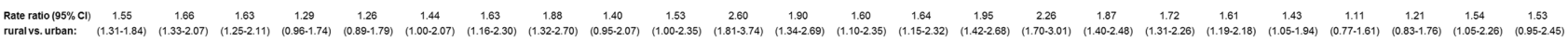

Figure 3 Risk of death among rural (blue) and urban (red) residing Canadian children, adolescents and young adults aged 1-24 years. Shown on the $\mathrm{Y}$-axis are age-specific mortality rates and $95 \% \mathrm{Cls}$, and below the $\mathrm{X}$-axis are age-specific rate ratios for mortality comparing those residing in rural vs urban areas.

supplementary file 2 . The characteristics of the children, and their mothers, are listed in table 1. There were 1609644 males and 1530054 females alive at age 366 days. About 7\% of all children were born preterm, and $8.2 \%$ of males and $6.3 \%$ of females were affected by a congenital or chromosomal anomaly (table 1). Of all children, $11 \%$ were residing in a rural area at age 1 year.

The median (IQR) duration of follow-up in the study period was 13.7 (7.7-20.4) years, and there were a total of 40733595 person-years of follow-up. There were 6930 deaths between ages 1 and 24 years, for an overall incidence rate of 17.0 (95\% CI 16.6 to 17.4 ) deaths per 100000 person-years. The age-specific mortality rate declined from 30.8 per 100000 at age 1 year to a low of 7.3 per 100000 at age 10 years (figure 1), and rose thereafter to a peak of 43.7 (95\% CI 37.7 to 49.7 ) per 100000 at age 23 years.

Of all 6930 deaths at ages 1-24 years, 4237 (61.1\%) were among males (20.3 per 100000 person-years) and 2693 (38.9\%) among females (13.6 per 100000 person-years)—an adjusted HR of 1.44 (95\% CI 1.37 to 1.51) (figure 2). Among all fatalities between age 1 and 24 years, the median (IQR) age at death was 12.4 (3.9-19.0) years for males and 8.2 (3.0-16.6) years for females. The unadjusted RR of death was higher among males than females at ages up to 3 years (figure 2), and again by age 14 years, where there was a notable rising separation in the risk of death, being 2.84 (95\% CI 1.93 to 4.20) times higher among males than females at age 24 years.

Compared with those within an urban area, children and youth residing in a rural area had an overall unadjusted HR of death of 1.60 (95\% CI 1.50 to 1.70), and an adjusted HR of 1.48 (95\% CI 1.39 to 1.58 ) (figure 3). At most ages, there was a higher risk of death among those living in a rural area (figure 3 ). There was a tendency for higher mortality with declining residential income (table 2). Compared with a child residing in the highest area income Q, those in the lowest income Q had an adjusted HR of 1.39 (95\% CI 1.29 to 1.51 ) for death at age 1-24 years. At both younger and later ages, the unadjusted RR was significantly higher in Q1 than Q5 areas, rising to 1.97 (95\% CI 1.26 to 3.08 ) by age 23 years (figure 4 ).

Compared with the children of a Canadian-born mother (15.4 per 100000 person-years), the mortality rate was slightly higher among those whose mother was from sub-Saharan Africa (16.0 per 100000 person-years), but not significantly so (adjusted HR $0.98,95 \%$ CI 0.81 to 1.19 ) (table 3). Those whose mother emigrated from South Asia, Hispanic America, other Western Nations or Europe and East Asia/Pacific were at a significantly lower risk for death.

A total of 5648 deaths in the cohort aged 1-24 years had a documented cause of death. In males, the proportion of deaths due to injury jumped at about age 15 years, from a mean of $30 \%$ before, to $65 \%$ thereafter $(\mathrm{p}<0.001)$ (online supplementary file $4 a)$. For females, there was a less pronounced rise at age 15 years, with a mean rate of $28 \%$ from age 1 to 14 years, and a mean rate of $51 \%$ from 15 to 24 years $(\mathrm{p}<0.001)$ (online supplementary

Table 2 Death of a child, adolescent or young adult between ages 1 and 24 years in relation to their residential income quintile, time varying at each year of age

\begin{tabular}{|c|c|c|c|}
\hline \multirow[b]{2}{*}{$\begin{array}{l}\text { Residential } \\
\text { income } \\
\text { quintile (Q) }\end{array}$} & \multirow{2}{*}{$\begin{array}{l}\text { Number of } \\
\text { deaths } \\
\text { (incidence rate } \\
\text { per } 100000 \\
\text { person-years) }\end{array}$} & \multicolumn{2}{|l|}{ HR $(95 \% \mathrm{Cl})$} \\
\hline & & Unadjusted & Adjusted $^{*} \dagger$ \\
\hline Q5 (highest) & $1248(14.7)$ & 1.00 (referent) & 1.00 (referent) \\
\hline Q4 & $1310(15.0)$ & 1.04 (0.96 to 1.12 ) & $1.02(0.94$ to 1.10$)$ \\
\hline Q3 & $1306(15.9)$ & 1.09 (1.01 to 1.18$)$ & 1.05 (0.97 to 1.14$)$ \\
\hline Q2 & 1319 (17.4) & 1.18 (1.09 to 1.28$)$ & 1.12 (1.03 to 1.21$)$ \\
\hline Q1 (lowest) & $1674(22.4)$ & 1.51 (1.41 to 1.63$)$ & 1.39 (1.29 to 1.51$)$ \\
\hline
\end{tabular}

*Adjusted for maternal world region of origin, age and liveborn parity at the child's birth, and the child's year of birth, sex, preterm birth $<37$ weeks' gestation, a congenital or chromosomal anomaly diagnosed before age 1 year and time-varying rurality. †17 023 participants had missing information about residential income quintile. Their corresponding adjusted HR was 1.58 (95\% $\mathrm{Cl} 1.20$ to 2.09$)$. 


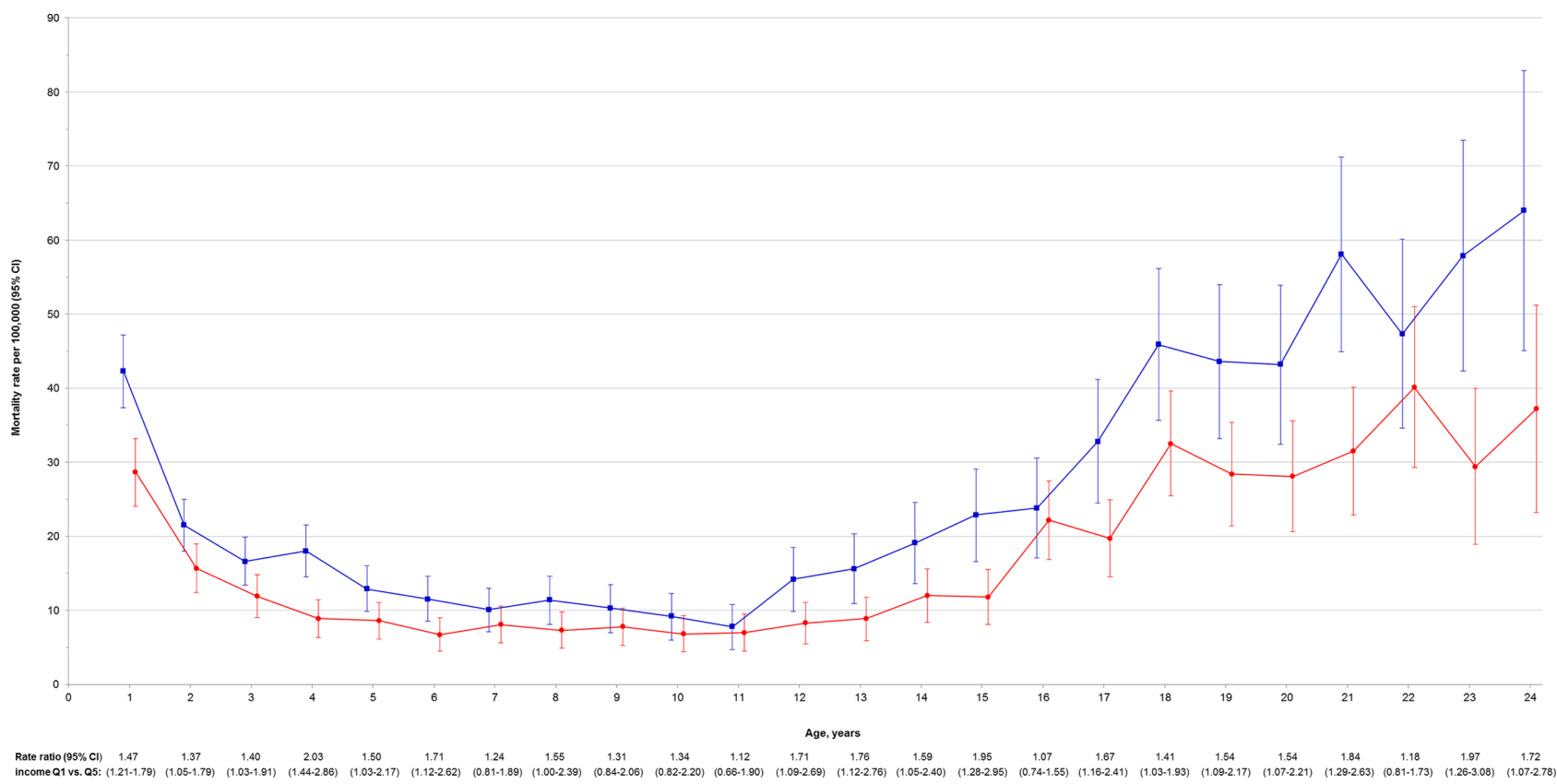

Figure 4 Risk of death among Canadian children, adolescents and young adults aged 1-24 years residing in the lowest (blue) and highest (red) area income quintiles (Q). Shown on the $\mathrm{Y}$-axis are age-specific mortality rates and $95 \% \mathrm{Cls}$, and below the $\mathrm{X}$-axis are age-specific rate ratios for mortality comparing those residing in the lowest (Q1) vs highest (Q5) areas.

file $4 b)$. The greatest proportion of deaths due to injury was at age 19 years for males $(77.2 \%)$ and at age 20 years for females (62.0\%). Among males, intentional causes (self-harm or assault/ homicide) explained $11 \%$ of injury-related deaths before age 15 years, and $20 \%$ of deaths from age 15 to 24 years (online supplementary file 4a). Accidental poisoning/overdose was the dominant cause of death due to injury in both male age groups (58\% and 43\%, respectively), followed by transport accident (31\%). In females, intentional causes explained 18\% of injuryrelated deaths before age 15 years, and $17 \%$ of deaths from age 15 to 24 years (online supplementary file $4 \mathrm{~b}$ ). Like males, accidental poisoning/overdose accounted for the largest proportion of injury-related deaths ( $46 \%$ and $44 \%$, respectively), followed by transport accident (35\% and 33\%, respectively). Of all deaths in each age group, the proportion occurring outside of hospital increased with age, especially after age 15 years (figure 5).

As the number of preceding liveborn siblings increased, so did a child's overall risk of dying from any cause (table 4, upper).
These HRs were more pronounced for deaths due to injury (table 4, lower) than from non-injury causes (table 4, middle).

In the 1:1 matched sibling analysis, there were 980 deaths among 565588 sisters (13.3 per 100000 person-years) and 1485 deaths among matched brothers (20.2 per 100000 personyears) — an unadjusted HR of 1.52 (95\% CI 1.40 to 1.65 ) and an adjusted HR of 1.46 (95\% CI 1.35 to 1.58 ).

\section{DISCUSSION}

In this large population-based cohort of $>3.1$ million live birthsrepresenting about 35\% of Canadian live births between 1990 and 2016, a J-shaped relation was observed between age and allcause mortality. Death in childhood and young adulthood was also more likely in rural and low-income areas, and among children whose mother originated from Canada, sub-Saharan Africa, the Caribbean or the Middle East/North Africa. Males tended to have a higher proclivity for death, especially from age 14 years

Table 3 Death of a child, adolescent or young adult between ages 1 and 24 years in relation to the child's mother's world region of origin, relative to Canadian-born women/long-term residents

\begin{tabular}{|c|c|c|c|}
\hline \multirow[b]{2}{*}{ Maternal world region of origin } & \multirow{2}{*}{$\begin{array}{l}\text { Number of deaths } \\
\text { (incidence rate per } 100000 \text { person-years) }\end{array}$} & \multicolumn{2}{|l|}{ HR $(95 \% \mathrm{Cl})$} \\
\hline & & Unadjusted & Adjusted ${ }^{*} \dagger$ \\
\hline Canada/long-term resident ( $\mathrm{n}=2111$ 160) & $4696(15.4)$ & 1.00 (referent) & 1.00 (referent) \\
\hline Sub-Saharan Africa $(n=53171)$ & $106(16.0)$ & $1.11(0.92$ to 1.35$)$ & $0.98(0.81$ to 1.19$)$ \\
\hline Caribbean $(n=43803)$ & $87(14.7)$ & $1.00(0.81$ to 1.24$)$ & $0.89(0.73$ to 1.10$)$ \\
\hline Middle East/North Africa ( $n=65942$ ) & $90(12.2)$ & $0.88(0.71$ to 1.09$)$ & $0.89(0.72$ to 1.10$)$ \\
\hline South Asia $(n=191263)$ & $262(12.0)$ & $0.88(0.77$ to 1.00$)$ & 0.87 (0.76 to 0.99$)$ \\
\hline Hispanic America $(n=54080)$ & $77(11.3)$ & $0.78(0.62$ to 0.98$)$ & 0.79 (0.63 to 0.98$)$ \\
\hline Western Nations/Europe $(n=110636)$ & $143(10.2)$ & 0.70 (0.59 to 0.83$)$ & $0.73(0.62$ to 0.86$)$ \\
\hline East Asia/Pacific ( $n=158250)$ & $189(10.1)$ & $0.71(0.62$ to 0.83$)$ & $0.78(0.67$ to 0.90$)$ \\
\hline
\end{tabular}

This analysis was restricted to children residing in an urban area at age 366 days after birth.

*Adjusted for maternal age and liveborn parity at the child's birth, and the child's year of birth, sex, preterm birth <37 weeks' gestation, a congenital or chromosomal anomaly diagnosed before age 1 year and time-varying residential income quintile and rurality.

†170 participants had missing information about maternal world region of origin. They were assigned to the Canada/long-term resident category. 


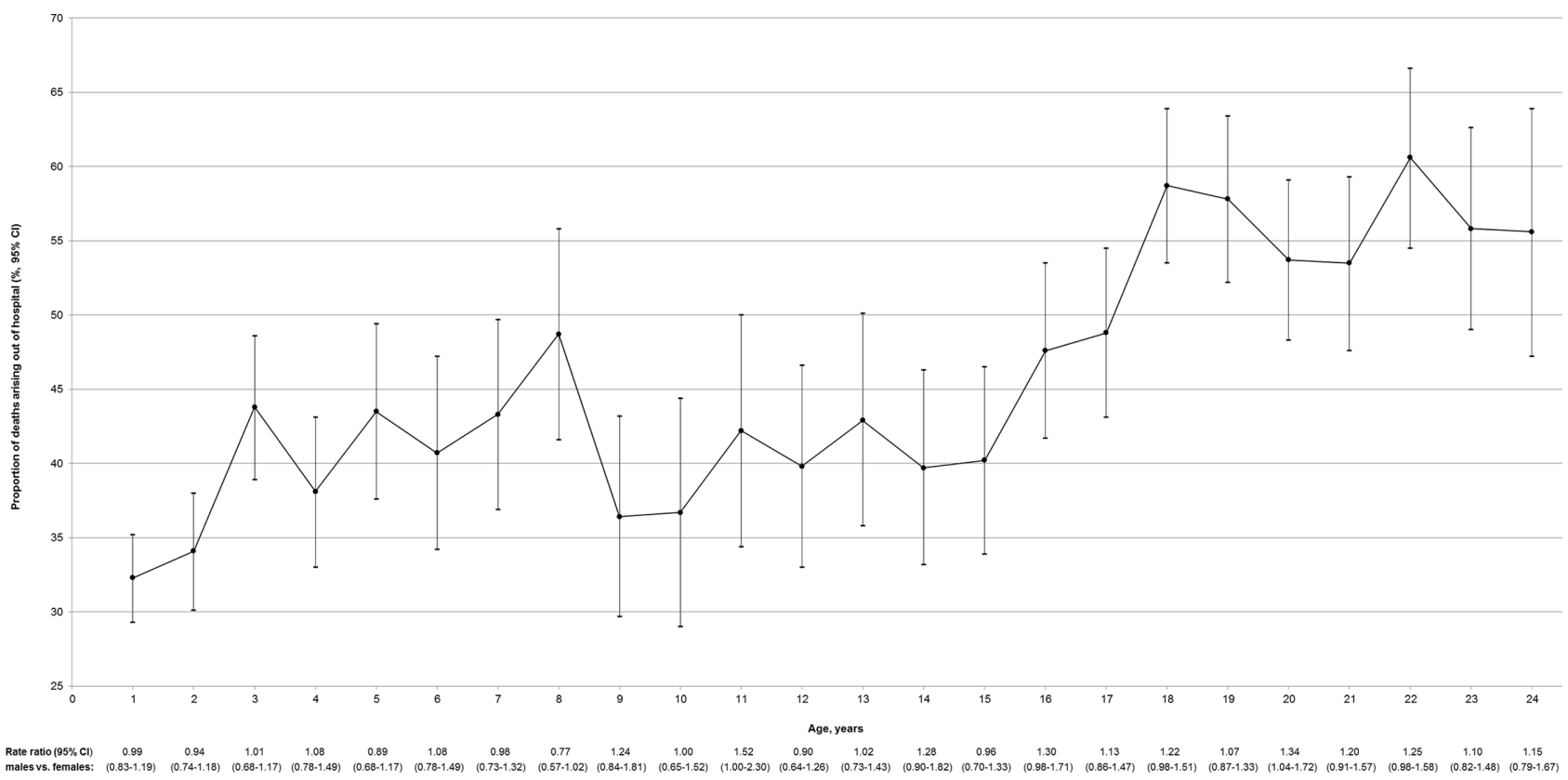

Figure 5 Proportion of all deaths occurring outside of a hospital setting, among Canadian children, adolescents and young adults aged 1-24 years. Shown on the Y-axis are age-specific proportions and $95 \% \mathrm{Cls}$ for deaths occurring outside of hospital, and below the X-axis are rate ratios for mortality comparing males vs females within each age group.

onwards, nearly tripling that of females by age 24 years. The proportion of deaths occurring outside of hospital also increased with age. Deaths due to injury massively rose after age 14 years, and accounted for $77 \%$ of male deaths at age 19 years and $62 \%$ of female deaths at age 20 years. Among those aged 15-24 years who died of injury, intentional causes explained one in five of male deaths, and one in six female deaths, while nearly half of injury deaths were due to accidental poisoning or overdose.

\section{Strengths and limitations}

A strength of the current study was the inclusion of a large cohort within a universal healthcare system, enabling a representative and precise estimation and comparison of mortality across an array of age groups and covariates, as well as by causes of death. As the median age at the end of follow-up was 13.7 years, most deaths among children who died before adolescence would be captured. For deaths in late adolescence or young adulthood, fewer youth contributed to the denominator of those at risk (see figure 1 , below the $\mathrm{X}$-axis).

This study relied on death certificate data to determine cause of death, yet, the accuracy of injury-related causes of death has been questioned. ${ }^{17}$ Not all deaths herein had a documented cause, nor was it known which deaths were confirmed by autopsy or an on-scene investigation. In adults, accidental poisonings now largely comprise prescription and illegal drug overdoses, ${ }^{18}$ and it is at the discretion of a medical examiner or coroner to

Table 4 Death of a child between ages 1 and 24 years in relation to the number of liveborn siblings preceding the birth of the current child

\begin{tabular}{|c|c|c|c|c|}
\hline & \multirow{2}{*}{$\begin{array}{l}\text { Number of preceding } \\
\text { liveborn siblings }\end{array}$} & \multirow{2}{*}{$\begin{array}{l}\text { Number of deaths } \\
\text { (incidence rate per } 100000 \text { person-years) }\end{array}$} & \multicolumn{2}{|l|}{$\mathrm{HR}(95 \% \mathrm{Cl})$} \\
\hline & & & Unadjusted & Adjusted* $†$ \\
\hline \multirow[t]{4}{*}{ Death due to any cause } & $0(n=1542071)$ & $3490(16.5)$ & 1.00 (referent) & 1.00 (referent) \\
\hline & $1(n=1101$ 167) & $2353(16.7)$ & 1.05 (1.00 to 1.11$)$ & 1.16 (1.10 to 1.23$)$ \\
\hline & $2(n=349689)$ & 699 (17.5) & 1.17 (1.08 to 1.27$)$ & $1.34(1.23$ to 1.45$)$ \\
\hline & $3+(n=139365)$ & $329(23.9)$ & 1.68 (1.50 to 1.89$)$ & $1.96(1.74$ to 2.21$)$ \\
\hline \multirow[t]{4}{*}{ Death due to non-injury } & $0(n=1542071)$ & $1727(8.2)$ & 1.00 (referent) & 1.00 (referent) \\
\hline & $1(n=1101$ 167) & $1104(7.8)$ & 0.95 (0.88 to 1.03$)$ & 1.08 (1.00 to 1.17$)$ \\
\hline & $2(n=349689)$ & $339(8.5)$ & $1.03(0.91$ to 1.15$)$ & 1.22 (1.08 to 1.37$)$ \\
\hline & $3+(n=139365)$ & $151(11.0)$ & 1.30 (1.10 to 1.54$)$ & 1.62 (1.36 to 1.92$)$ \\
\hline \multirow[t]{4}{*}{ Death due to injury } & $0(n=1542071)$ & $1111(5.3)$ & 1.00 (referent) & 1.00 (referent) \\
\hline & $1(n=1101167)$ & $837(5.9)$ & $1.20(1.10$ to 1.31$)$ & 1.39 (1.27 to 1.52$)$ \\
\hline & $2(n=349689)$ & $219(5.5)$ & 1.24 (1.07 to 1.43$)$ & 1.60 (1.38 to 1.86$)$ \\
\hline & $3+(n=139365)$ & $105(7.6)$ & 1.96 (1.59 to 2.42$)$ & 2.77 (2.23 to 3.45$)$ \\
\hline
\end{tabular}

Shown are deaths from any cause (upper), non-injury causes (middle) and injury causes (lower).

*Adjusted for maternal world region of origin, age at the child's birth and the child's year of birth, sex, preterm birth <37 weeks' gestation, a congenital or chromosomal anomaly diagnosed before age 1 year and time-varying residential income quintile and rurality.

†7406 participants had missing information about the number of preceding liveborn siblings. Their corresponding adjusted $\mathrm{HRs}$ were 2.47 (95\% $\mathrm{Cl} 1.90$ to 3.21 ) for death due to any cause, 3.70 ( $95 \% \mathrm{Cl} 2.73$ to 5.02 ) for death due to non-injury and 1.50 ( $95 \% \mathrm{Cl} 0.81$ to 2.78 ) for death due to injury. 
determine whether they are deemed 'accidental', based on the circumstances and evidence surrounding the death. ${ }^{19}{ }^{20}$ Some suicides continue to be misclassified as accidental poisonings or a death of unknown intent, especially in the more recent era of opioid use. ${ }^{21} 22$ In 2013-14, of all intentional self-harm hospitalisations among Canadian youth aged 10-17 years, poisoning made up $88 \%$ of events among girls and $82 \%$ of events in boys. ${ }^{23}$ More than $50 \%$ of poisonings among Canadian youth presenting to hospital are intentional..$^{24}$ Given the above, and the observations herein that accidental poisoning and overdose accounted for nearly half of all injury-related deaths, and that greater than half of all deaths occurred out of hospital by age 18 years, is it conceivable that more adolescent deaths were from suicide than realised.

The relation between some variables studied herein and the risk of death could still be explained by unmeasured confounding. However, at least for the comparison of mortality between males and females, it is unlikely that residual confounding persisted, since the sibling analysis generated a similar adjusted HR (1.46, $95 \% \mathrm{CI} 1.35$ to 1.58$)$ as the non-sibling analysis $(1.44,95 \% \mathrm{CI}$ $95 \%$ CI 1.37 to 1.51 ). Nevertheless, this study did not detail important factors in child development, including mental illness (eg, attention deficit hyperactivity disorder (ADHD) or bipolar disorder ${ }^{25}$ and educational attainment, nor were parental marital status or parental-child engagement assessed.

\section{Mechanisms of disease}

The elevated rate of death before age 1 year is known to be largely related to prematurity, major anomalies and sudden infant death syndrome. ${ }^{78}$ While those influential factors may have persisted herein over the second to fourth years of life (figure 1), they were accounted for in the multivariable models. By age 12 years, the youth mortality rate started to climb, especially from fatal injuries starting at about age 15 years. It is around this age that greater risk-taking behaviour begins, especially among males and individuals with ADHD or conduct disorder, ${ }^{26}$ as well as those with psychosocial factors that limit self-regulation. ${ }^{27}$ As succinctly summarised elsewhere, self-destructive behaviours typically arise from predisposing biological, personality and cognitive vulnerabilities, worsened by further exposure to negative life events and psychiatric disorders. ${ }^{28}$ In the USA, intentional injury has been correlated with degree of community-level poverty, ${ }^{29} 30$ as was similarly shown herein. Low-income status and parental education were each associated with poorer coping strategies among Danish adolescents. ${ }^{31}$ Consistent with a previous Swedish study, ${ }^{15}$ we found that the risk of all-cause mortality increased with the number of older siblings; however, the Swedish authors did not assess adolescent mortality at age 11-19 years or causespecific mortality in children/youth due to small numbers.

Recent mortality data from the USA has shown a concerning rise in premature adult deaths due to drug poisoning, especially among white people and those residing in rural counties. ${ }^{5}$ Herein, mortality followed a similar pattern, with a $50 \%$ overall relative higher mortality in rural areas, including a $237 \%$ relative increase within the 11-year age group. While the health of Canadian youth born to immigrants is generally better than their non-immigrant peers, ${ }^{32}{ }^{33}$ the current study did not show such a protective effect among the offspring of mothers from the Caribbean, sub-Saharan Africa and the Middle East (table 3). We do not know how our findings might differ from those of children that arrived as immigrants to Canada. Thus, while there are clearly many factors that contribute to child death, prevention programmes should not lose sight of these sizeable groups, whose susceptibility to premature death may be rising over time. ${ }^{5}$

\section{Implications for policy and clinical practice}

These findings reinforce observations from the USA and elsewhere ${ }^{4}$ : there is clearly a susceptibility to dying among specific subgroups of children and youth, with a predilection for death due to intentional and unintentional injury with rising age, ${ }^{34}$ especially at age 15 years. These data certainly suggest that injury prevention strategies should be initiated before age 15 years, including ongoing efforts to reduce pedestrian, passenger and driver injury, ${ }^{35}{ }^{36}$ for land vehicles, and for watercraft as well. ${ }^{37}$

A concerning high proportion of injury deaths during adolescence and early adulthood are from intentional causes, including self-harm. Others have shown that many of these victims have an existing or unrealised psychiatric condition, especially a mood disorder or ADHD. ${ }^{38}$ As another highly susceptible group, a large Danish case-control study of adults aged 15-35 years showed that the risk of unnatural death was 5.3 times higher in those with a history of violence, 12.7 times greater with a history of self-harm and 29.4 times higher with a record of both behaviours. ${ }^{39}$ There may also be time-specific climbs in self-harm among youth, such as during periods of economic recession. ${ }^{40}$

In response, it has been suggested that multiple strategies are needed to reduce self-harm among youth. At the individual level, one approach includes cognitive behavioural therapy, to reduce rash reactivity to emotions and to improve self-regulation. ${ }^{41}$ At the broader public health level, examples include improving access to suicide prevention clinics, restricting the purchase of non-opioid over-the-counter analgesics and the quantity within each medication pack, ${ }^{40}$ and limiting adolescent access to firearms in high-availability regions. ${ }^{42}$

Given their high occurrence in childhood and young adulthood, more in-depth study is clearly needed on poisonings and overdoses, and the degree to which some are intentional, rather than accidental, in nature. The latter creates an important opportunity for improving our community processes in confirming the probability that suicide accounts for a larger than realised proportion of such deaths. Likewise, linkages of mortality data to other health and demographic data can facilitate more nuanced deconstruction of mortality rates, to enable more precise public health initiatives.

\section{CONCLUSION}

There is a heightened susceptibility of dying starting at age 15 years, especially among males, from injury, and arising outside of hospital.

\section{What is already known on this subject}

Prior research on deaths in childhood largely included those occurring in the first year of life and thereafter, while omitting those occurring after age 20 years.

- Most prior studies were done in jurisdictions where universal access to healthcare was not available, potentially biasing their findings on the frequency, causes, and nature of deaths in childhood, adolescence and early adulthood. 


\section{What this study adds}

- A novel birth cohort was created within a universal healthcare system, using linked population-based datasets.

- This enabled the exploration of associations between deaths at age 1-24 years with maternal immigration, time-varying income status, sibling order and cause of death.

- Valid measures (internally and externally) generated precise estimates of risk by age, and from 1 to 24 years.

- There is clearly a susceptibility to dying among specific subgroups of children and youth, with a predilection for death due to intentional and unintentional injury with rising age.

- In addition to initiation of injury prevention strategies at age 15 years, the focus should be on a disproportionate number of injury deaths during adolescence and early adulthood from self-harm and unrealised psychiatric conditions.

- More in-depth study is especially needed on poisonings and overdoses, and the degree to which some are intentional, rather than accidental, in nature.

Contributors JGR, ALP: study concept, analysis and interpretation of the data, drafting of manuscript, manuscript revision, approval of final version. AG, JS: analysis and interpretation of the data, manuscript revision, approval of final version.

Funding This study was supported by ICES, which is funded by an annual grant from the Ontario Ministry of Health and Long-Term Care (MOHLTC). This study was also received funding from the Canadian Institutes of Health Research (CIHR).

Disclaimer The funders had no role in study design, data collection and analysis, decision to publish or preparation of the manuscript. Parts of this material are based on data and information compiled and provided by MOHLTC and CIHI. The analyses, conclusions, opinions and statements expressed herein are those of the author and do not necessarily reflect those of the funding or data sources; no endorsement is intended or should be inferred. Parts of this report are based on Ontario Registrar General information on deaths, the original source of which is ServiceOntario. The views expressed therein are those of the author and do not necessarily reflect those of ORG or Ministry of Government Services.

Competing interests None declared.

Patient consent for publication Not required.

Provenance and peer review Not commissioned; externally peer reviewed.

Data availability statement No data are available.

Open access This is an open access article distributed in accordance with the Creative Commons Attribution Non Commercial (CC BY-NC 4.0) license, which permits others to distribute, remix, adapt, build upon this work non-commercially, and license their derivative works on different terms, provided the original work is properly cited, appropriate credit is given, any changes made indicated, and the use is non-commercial. See: http://creativecommons.org/licenses/by-nc/4.0/.

ORCID iD

Joel G Ray http://orcid.org/0000-0003-1635-4658

\section{REFERENCES}

1 Jonas D, Scanlon C, Rusch R, et al. Bereavement After a Child's Death. Child AdolesC Psychiatr Clin N Am 2018;27:579-90.

2 White A, Holmes M. Patterns of mortality across 44 countries among men and women aged 15-44 years. J Men's Health \& Gender 2006;3:139-51.

3 Wahlbeck K, Westman J, Nordentoft M, et al. Outcomes of Nordic mental health systems: life expectancy of patients with mental disorders. Br J Psychiatry 2011;199:453-8.

4 Khan SQ, Berrington de Gonzalez A, Best AF, et al. Infant and youth mortality trends by Race/Ethnicity and cause of death in the United States. JAMA Pediatr 2018:172:e183317.

5 Shiels MS, Berrington de González A, Best AF, et al. Premature mortality from all causes and drug poisonings in the USA according to socioeconomic status and rurality: an analysis of death certificate data by County from 2000-15. Lancet Public Health 2019;4:e97-106.
6 Special Advisory Committee on the Epidemic of Opioid Overdoses. National report: apparent opioid-related deaths in Canada (January 2016 to September 2018). web based report. Ottawa: public health agency of Canada, April 2019. Available: https:// health-infobase.canada.ca/datalab/national-surveillance-opioid-mortality.html [Accessed 29 May 2019].

7 Ray JG, Park AL, Fell DB. Mortality in infants affected by preterm birth and severe Small-for-Gestational age birth weight. Pediatrics 2017;140:e20171881.

8 Tomashek KM, Hsia J, lyasu S. Trends in postneonatal mortality attributable to injury, United States, 1988-1998. Pediatrics 2003;111:1219-25.

9 WHO Multicentre Growth Reference Study Group. Who motor development study: windows of achievement for six gross motor development milestones. Acta Paediat Supp/ 2006;450:86-95

10 Chiu M, Lebenbaum M, Lam K, et al. Describing the linkages of the immigration, refugees and citizenship Canada permanent resident data and vital statistics death registry to Ontario's administrative health database. BMC Med Inform Decis Mak 2016;16:135.

11 Cunningham RM, Walton MA, Carter PM. The major causes of death in children and adolescents in the United States. N Engl J Med 2018;379:2468-75

12 Jonckheere AR. A distribution-free $K$-Sample test against ordered alternatives. Biometrika 1954;41:133-45.

13 Ray WA, Chung CP, Murray KT, et al. Out-Of-Hospital mortality among patients receiving methadone for noncancer pain. JAMA Intern Med 2015;175:420-7.

14 Scholer SJ, Mitchel Jr EF, Ray WA. Predictors of injury mortality in early childhood. Pediatrics 1997:100:342-7.

15 Modin B. Birth order and mortality: a life-long follow-up of 14,200 boys and girls born in early $20^{\text {th }}$ century Sweden. Soc Sci Med 2002;54:1051-64.

16 Frisell T, Öberg S, Kuja-Halkola R, et al. Sibling comparison designs: bias from nonshared confounders and measurement error. Epidemiology 2012:23:713-20.

17 Hodgson NF, Stewart TC, Girotti MJ. Autopsies and death certification in deaths due to blunt trauma: what are we missing? Can J Surg 2000:43:130-6.

18 Paulozzi LJ, Ballesteros MF, Stevens JA. Recent trends in mortality from unintentional injury in the United States. J Safety Res 2006;37:277-83.

19 Miech R, Koester S, Dorsey-Holliman B. Increasing us mortality due to accidental poisoning: the role of the baby boom cohort. Addiction 2011;106:806-15.

20 Shepherd G, Klein-Schwartz W. Accidental and suicidal adolescent poisoning deaths in the United States, 1979-1994. Arch Pediatr Adolesc Med 1998:152:1181-5.

21 Bohnert ASB, Roeder K, Ilgen MA. Unintentional overdose and suicide among substance users: a review of overlap and risk factors. Drug Alcohol Depend 2010;110:183-92.

22 Skinner $\mathrm{R}, \mathrm{McF}$ Fuull $\mathrm{S}$, Rhodes $\mathrm{AE}$, et al. Suicide in Canada: is poisoning misclassification an issue? Can J Psychiatry 2016;61:405-12.

23 Intentional Self-Harm Among Youth in Canada. Canadian Institute for health information, 8998-1014. Available: https://www.cihi.ca/web/resource/en/info_child harm_en.pdf [Accessed 21 May 2019].

24 Canadian Institute for Health Information. Canadian centre on substance abuse. hospitalizations and emergency department visits due to opioid poisoning in Canada. Ottawa, ON: CIHI, 2016.

25 Marangoni C, De Chiara L, Faedda GL. Bipolar disorder and ADHD: comorbidity and diagnostic distinctions. Curr Psychiatry Rep 2015;17:604.

26 Crone EA, van Duijvenvoorde ACK, Peper JS. Annual Research Review: Neural contributions to risk-taking in adolescence - developmental changes and individual differences. J Child Psychol Psychiatr 2016;57:353-68.

27 Steinberg L. Risk taking in adolescence: what changes, and why? Ann N Y Acad Sci 2004:1021:51-8.

28 Hawton K, Saunders KEA, O'Connor RC. Self-Harm and suicide in adolescents. Lancet 2012:379:2373-82

29 Guyer B, Lescohier I, Gallagher SS, et al. Intentional injuries among children and adolescents in Massachusetts. N Engl J Med 1989:321:1584-9.

30 Engström K, Diderichsen F, Laflamme L. Socioeconomic differences in injury risks in childhood and adolescence: a nation-wide study of intentional and unintentional injuries in Sweden. Inj Prev 2002;8:137-42.

31 Glasscock DJ, Andersen JH, Labriola M, et al. Can negative life events and coping style help explain socioeconomic differences in perceived stress among adolescents? A cross-sectional study based on the West Jutland cohort study. BMC Public Health 2013;13:532.

32 Beiser M, Hou F, Hyman I, et al. Poverty, family process, and the mental health of immigrant children in Canada. Am J Public Health 2002:92:220-7.

33 Saunders NR, Lee $H$, Macpherson A, et al. Risk of firearm injuries among children and youth of immigrant families. Can Med Assoc J 2017;189:E452-8.

34 Centers for Disease Control and Prevention (CDC). Vital signs: Unintentional injury deaths among persons aged 0-19 years - United States, 2000-2009. MMWR Morb Mortal Wkly Rep 2012;61:270-6.

35 Hadland SE, Xuan Z, Sarda V, et al. Alcohol policies and alcohol-related motor vehicle crash fatalities among young people in the US. Pediatrics 2017;139:e20163037.

36 Wolf LL, Chowdhury R, Tweed J, et al. Factors associated with pediatric mortality from motor vehicle crashes in the United States: a state-based analysis. J Pediatr 2017; 187:295-302. 
37 Boyle TA, Rao KA, Horkan DB, et al. Analysis of water sports injuries admitted to a pediatric trauma center: a 13 year experience. Pediatr Surg Int 2018;34:1189-93.

38 Hawton K, Saunders K, Topiwala A, et al. Psychiatric disorders in patients presenting to hospital following self-harm: a systematic review. J Affect Disord 2013;151:821-30

39 Steeg S, Webb RT, Mok PLH, et al. Risk of dying unnaturally among people aged 15-35 years who have harmed themselves and inflicted violence on others: a national nested case-control study. Lancet Public Health 2019;4:e220-8.
40 Steeg S, Carr MJ, Mok PLH, et al. Temporal trends in incidence of hospital-treated selfharm among adolescents in Denmark: national register-based study. Soc Psychiatry Psychiatr Epidemiol 2019;53.

41 Lockwood J, Daley D, Townsend E, et al. Impulsivity and self-harm in adolescence: a systematic review. Eur Child Adolesc Psychiatry 2017;26:387-402.

42 Simonetti JA, Mackelprang JL, Rowhani-Rahbar A, et al. Psychiatric comorbidity, suicidality, and in-home firearm access among a nationally representative sample of adolescents. JAMA Psychiatry 2015;72:152-9. 